\title{
Analysis of High School Students' Errors in Solving Trigonometry Problems
}

\author{
Jacob Arhin ${ }^{1}$, Evans Kofi Hokor ${ }^{2 *}$ \\ ${ }^{1}$ Kumasi Anglican Senior High School, GHANA \\ ${ }^{2}$ St. Teresa's College of Education, Hohoe, GHANA \\ *Corresponding Author: evanskhokor@gmail.com \\ Citation: Arhin, J., \& Hokor, E. K. (2021). Analysis of High School Students' Errors in Solving Trigonometry Problems. Journal of Mathematics and \\ Science Teacher, 1(1), em003. https://doi.org/10.29333/mathsciteacher/11076

\begin{tabular}{|c|c|}
\hline ARTICLE INFO & ABSTRACT \\
\hline Received: 6 May 2021 & This study examined High School students' error displayed in solving trigonometry problems. The literature \\
\hline Accepted: 19 Jun. 2021 & $\begin{array}{l}\text { revealed that trigonometry is difficult for students to understand and our paper contends that identifying } \\
\text { students' error and understanding how the errors occurred can serve as a point of reference for instructional } \\
\text { decisions which will make the concept easier. The study uses a quantitative research techniques to explore } \\
\text { students' errors in solving trigonometry problems. Ninety students were sampled using multistage sample } \\
\text { techniques. Trigonometry Achievement Test (TAT) was used in data collection. Descriptive statistics (figures and } \\
\text { tables) was used to present the students' error after content analysis was carried out and Modified Newman's Error } \\
\text { Hierarchy was used in classifying students' error. The results revealed most students' errors occurs at } \\
\text { transforming, processing and encoding stages. Independent sample t-test was used to compare the errors } \\
\text { committed by male and female students. Independent samples t-test of groups' differences in means among male } \\
\text { and female students indicated that, there was a significant difference in their mean scores at } t(89)=2.198, p<.05 \text {. } \\
\text { Thus, female students' level of committing errors in solving trigonometry problems was significantly higher than } \\
\text { their male counterparts. The study recommends that Mathematics teachers should make the teaching of } \\
\text { trigonometry practical and more activity-oriented to limit students' error in solving trigonometry problem most } \\
\text { importantly among the female students. }\end{array}$ \\
\hline
\end{tabular}

Keywords: high school mathematics, teaching trigonometry, trigonometry errors, mathematics teachers

\section{INTRODUCTION}

The concepts of mathematics are applied in various fields of study such as economics, engineering, sciences, medicine, and business. Trigonometry is an important component of mathematics curriculum. It is one of the most important content domains in the High School mathematics curriculum because it links algebraic, geometric and graphical reasoning together. Trigonometry can serve as an important precursor to calculus as well as college level courses relating to Newtonian Physics, architecture, surveying and engineering. Unfortunately, many high school students are not accustomed to these types of reasoning (Welber, 2008), and learning about trigonometric functions is initially fraught with difficulty. This is because trigonometry presents many first - time challenges for students as it requires students to relate diagrams of triangles to numerical relationships and manipulates the symbols involved in such relationships. Trigonometric functions are typically among the first functions that students cannot evaluate directly by performing arithmetic operations. Students' errors are causally determined, and very often systematic. Systematic errors are usually consequences of students' misconceptions. These can include failure to make connections with what they already know. There are beliefs held by students that inhibit learning from errors, such that they cannot learn from mistakes and that mathematics consist of disconnected rules and procedures. Student's errors are unique and they reflect their understanding of concept, problem or a procedure (Sarwadi \& Shahrill, 2014) and students' errors are the symptoms of misunderstanding (Lai, 2006). This indicates exploring errors students displayed would provide teachers with the extent to which the student has mastery of a particular mathematical concept and this can lead to instructional reforms. Among many different types of errors, systematic errors occur to many students over a long period. The causes of systematic errors may relate to students' procedural knowledge, conceptual knowledge, or links between these two types of knowledge. Errors can be mistakes, blunders, miscalculations, or misjudgment and such category falls under systematic errors (Muzangwa \& Chifamba, 2012).

Trigonometry is one of the mathematics topics which has become the bane to many students such that they have to strive to obtain a pass (Usman \& Muhammed, 2017). Many mathematics teachers in introducing trigonometric ratios to students draw many right-angled triangles with the same angles located in the same place of the triangle and to explore the ratio of sides. Such an 
activity continues to be worthwhile, although it is tedious and, of course, somewhat error-prone when students measure and use that approach (Kissane \& Kemp, 2009). The term trigonometry is difficult to define mathematically. In a study conducted by (Wilderger, 2007) entitled "the rational teaching of trigonometry" the author assert that trigonometry is difficult to define explicitly in mathematics contexts. Trigonometry can be defined in two ways, these are the etymological approach, and historical background approach. The etymological approach to trigonometry refers to a combination of the Greek words "Tri" being the prefix meaning three, "gon" referring to a polygon (e.g., pentagon, hexagon etc.) and "metry" referring to measure (Fanning, 2016). Putting all together, trigonometry is the study and the measure of three-sided polygon. Antoro et al. (2015) agreed that trigonometry is derived from Greek words, however, disagreed on the number of words. These are 'trigonon' which means three corners and 'metro' means measure. Trigonometry is a branch of mathematics that deals with the angles and lengths of triangle. Also, trigonometry is the study of anything pertaining to angles, triangles, or the functions of sine, cosine and tangent. The difficulty with defining trigonometry may be the origin of students' errors.

\section{Students' Errors in Learning Mathematics}

Error is regard as a mistake in the process of solving a mathematical problem algorithmically, procedurally or by any other method. Even though teachers have access to learners' work and teachers are aware of some of their errors but there is no demand on teachers to use learners' errors as building blocks for teaching and learning (Sapire et al., 2016). Teachers can use students' error as a prerequisite skill (Relevant Previous Knowledge) for a new topic to be introduced. Using error analysis in teaching mathematics is not a common practice in mathematics classroom, (Rushton, 2018) because mathematics teaching strategies has depend mostly on teachers demonstrating correctly worked examples as models for students to imitate without practicing their own exercises and strategies. Incorrect exercise has been in recent years introduced for the purpose of students to conduct Error Analysis (Rushton, 2018). It is very helpful in ensuring students understanding retention. This means that using this method as a strategy in teaching mathematics will contribute to students' retention. In ensuring proper use of Error Analysis Barlow et al. (2018) suggested that teachers should know which mistakes to inspect and why. Teachers must stress on what may possibly lead to an error for students not to commit such errors. Students' mistakes cannot not be limited to a computational error alone; rather these mistakes include mathematical thinking, answers, and strategies that are either incorrect or unjustifiable (Barlow et al., 2018). Rushton (2018) explained procedural error as mistakes in algorithms or other routine procedures. Inspecting procedural errors provide not only identity and correcting the errors but also justify the reasoning behind correct procedures. Error Analysis should be used as methods of teaching because specific errors identification is important for students with learning difficulties and low performing students (Lai, 2006).

\section{Gender Issues in Learning Mathematics}

The issue of gender in mathematics education had raised concerns in the world. Many countries in the world have made documentation and passed legislations to support the achievement of gender disparity and equity in mathematics and science education (Leder, 2015). However, gender differences in mathematics performance and participation in post-contemporized mathematics courses still favors the male students' in many countries. Gaisman (2015) in Mexico studies the performance of boys and girls in mathematics at the basic level and report no significant difference. However, at the High School level the performance in mathematics with respect to boys and girls shows significant difference. This difference favours boys. This means that in Mexico at the secondary school level the performance of boys in mathematics outweigh that of girls at the secondary school level but at the primary level the performance is the same. Only $38 \%$ of the entire female population take either mathematics or mathematics related subjects in Mexico (Saavedra \& Garcia Belaude, 2010). The gender gap enlarges when considering access to post- graduate education. For example, in 2008 only $30 \%$ of students in post - graduate programs were women, out of these number, $45 \%$ took mathematics and mathematics related subjects (Gaisman, 2015). Even though the study acknowledges some progress been made in Mexica, it calls for policy direction to change socio-cultural perceptions, which inhibits the development of women in mathematics related areas. More efforts are needed to increase participation of women in decision making in mathematics to boost the love of women studying Mathematics, Science and Technology. Study conducted in Australia by Forgasz (2015) identified four areas in which gender equity in mathematics education has not yet been fully achieved. These areas are

i. Achievement in TIMSS and Program for International Students Assessments (PISA);

ii. Participation and achievement in higher level mathematics;

iii. Use of technologies for mathematics learning and;

iv. Public perceptions of gender issues in mathematics.

Australia results in all years of TIMSS for grade four (4) and grade eight (8) show an increasing gap favouring males while in PISA the gap is still present favoring male. The author noted that enrolments have declined over time in specialist mathematics while increasing in further mathematics, however, consistently, there have been higher proportion of males than females enrolled in all the options. This may be as a results of the view by many people that mathematics is for boys which tend to influence girls perception toward mathematics.

Study by Brown and Kanyongo (2010) in Trinidad and Tobago on gender differences in mathematics performance: examining affective factors. The findings from this study show that there is a gender differential in mathematics performance in favour of girls in Trinidad and Tobago. The findings also revealed that there is no difference between boys and girls in terms of perception of school environment, educational values and goals and general academic self-concept. In the area of mathematics, the consistency of girls practicing mathematics is higher than their boys counterpart, nevertheless, they hold lower mathematics selfconcept than their boys counterpart. On the contrary, Tommaso et al. (2016) study in Italy on the gender gap in mathematics achievement shows that girls systematically underperform boys, even after controlling for individual and family background 
characteristics, and that the average gap increases with children's age. Debra (2017) noted that improvements over the past decade on gender equality and equity among South Africa women continue to be underrepresented in tertiary education (studies) and professional careers in the field of Science, Technology, Engineering and Mathematics. This may lead to poor participation of female in the field of Science, Technology, Engineering and Mathematics and this has an implication not only for an economic development and growth, but also for social inequality as many women continue to have less access to high paying employment opportunities.

According to Brijlall (2014) content knowledge is the specialized knowledge needed by teachers, and to be used in a unique way in teaching. It's use is only necessary for the purposes of imparting mathematical content knowledge to others. The teachers have to learn to acquire various strategies of solving the problems especially in trigonometry, nevertheless, content knowledge alone is not sufficient for effective delivery of the lessons. Teachers also need pedagogical knowledge and the curriculum knowledge in addition. It should be known to the teacher what the learner will think and their reaction to specific information should be anticipated (Brijlall, 2014). The teacher should know the type of context that will be interesting and easy to understand to his/her learners. This includes the ability to choose tasks that students will find motivating as well as the ability to identify errors that will be common to his/her learners (Brijlall, 2014). This helps teachers in making correct choices and taking the right decisions about the mathematics they teach. Teachers' preferences and opinions regarding pedagogical techniques in mathematics courses are important, because they may reveal their ability to address the needs of students at different learning levels (Unal, 2017). Many teaching techniques were valued for their tendency to facilitate active participation, hands-on- activities, and practical activities; in other words, courses were mostly organized around students centered activities. It is appearing that effective mathematical teaching and learning are possible only when aided by activities requiring students' active participation (Unal, 2017). An activity is well constructed when teachers have good understanding of their learners. Therefore, identifying students' errors and understanding what possibly led to such errors would create consciously among teachers on what to say and how to say it during teaching. For when a man in front falls, others behind take caution. Therefore, students will also be careful when solving trigonometry problems because they know the errors committed by others.

While many researches explore errors in trigonometry in general, the specific error exploration in the area of angle of elevation, depression and bearing appear to be scarce. Additionally, there's inconsistency in the findings related to male and female students committing errors in trigonometry problem solving. Therefore, this study is initiated to fill the above gaps. This study therefore provide an empirical assessment of Senior High School students' errors in solving trigonometry problems with the view to explore the nature and the origin of these errors. Based on the purpose and the literature review, the study seeks to answer the following research questions.

1. What errors do SHS students make in solving trigonometry problems?

2. Is there any significant difference between the level of committing errors in solving trigonometry problems among male and female SHS students?

In order to answer research question two, hypothesis was set as.

Ho: There is no significant difference between the means of students' test scores among the two groups (male and female groups).

The answer to the above questions would help advance knowledge based on Mathematics by providing the insight of students' errors and how teaching should be structured to limit the extent to which students commit errors when solving trigonometry problems. Information about students' errors on bearing, angle of elevation and depressions could contribute to teachers' classroom instructional decision which will help improve teaching and learning of mathematics. Finally, creating awareness among teachers on the errors committed by students on trigonometry problem solving can help prevent or limit the errors since teachers can design activities that indirectly provide clarifications to what is likely to lead to such errors.

\section{THEORETICAL REVIEW}

Theoretical framework is derived from an existing theory (or theories) in the literature that has already been tested and validated by others and it is considered a generally acceptable theory in the scholarly literature (Grant \& Osanloo, 2014). Newman (1977) has been proven to be a reliable model for mathematics teachers to be used to classify and categorize students' errors (Prakitipong \& Nakamura, 2006; Effandi, 2010). Newman (1977) created a model to assess students difficulties in solving mathematical word problems, in which the author categorized students' errors in five ways which are reading errors, comprehension errors, transformation errrors, processes errors, and encoding errors.

1. Reading Errors: Mistakes made in the resolution of problems are classified as reading error if students cannot read key words or symbols written on the problem.

2. Comprehension Errors: Students are able to read all the words in question but they do not understand the overall meaning of the words so that students are not able to go further along the right channels for resolving the problems.

3. Transformation Errors: Students have been able to read and understand the problem or the question but cannot diagrammatically represent the information or they are not able to identify the operation or sequence of operations required to resolve the problem.

4. Process Skill Errors : Students recognize the operation or sequence of operations, but they do not know the procedures necessary to carry out the operation accurately 
5. Encoding Errors: Students correctly solve the problem, but, cannot express the solution in the form of appropriate notation which can be accepted as a conclusion. Students are able to solve these problems, but in doing inference, answers do not match with the demand of the problem.

The researchers combined Reading and Comprehension in one level because if a student is able to comprehend, then most possibly he or she can read. Additionally, most high school students do not have difficulty with reading. Table 1 present modified Newman's (1977) error analysis model for the classification of errors.

Table 1. Modified Newman's Error Hierarchical Model

\begin{tabular}{lll}
\hline Skills Criteria & Newman's Error Hierarchical level \\
\hline i. & Defining variables & Reading and Comprehension \\
ii. & Showing diagram, if required & \\
iii. & Writing correct mathematical expression & Transformation \\
iv. $\quad$ Finding the required variable & Process skills \\
v. $\quad$ Substituting correctly into the trigonometric expression & \\
vi. $\quad$ Finding the value of the variable & \\
vii. & Arriving at the correct answer & Encoding \\
\hline
\end{tabular}
(Adapted from Newman, 1977)

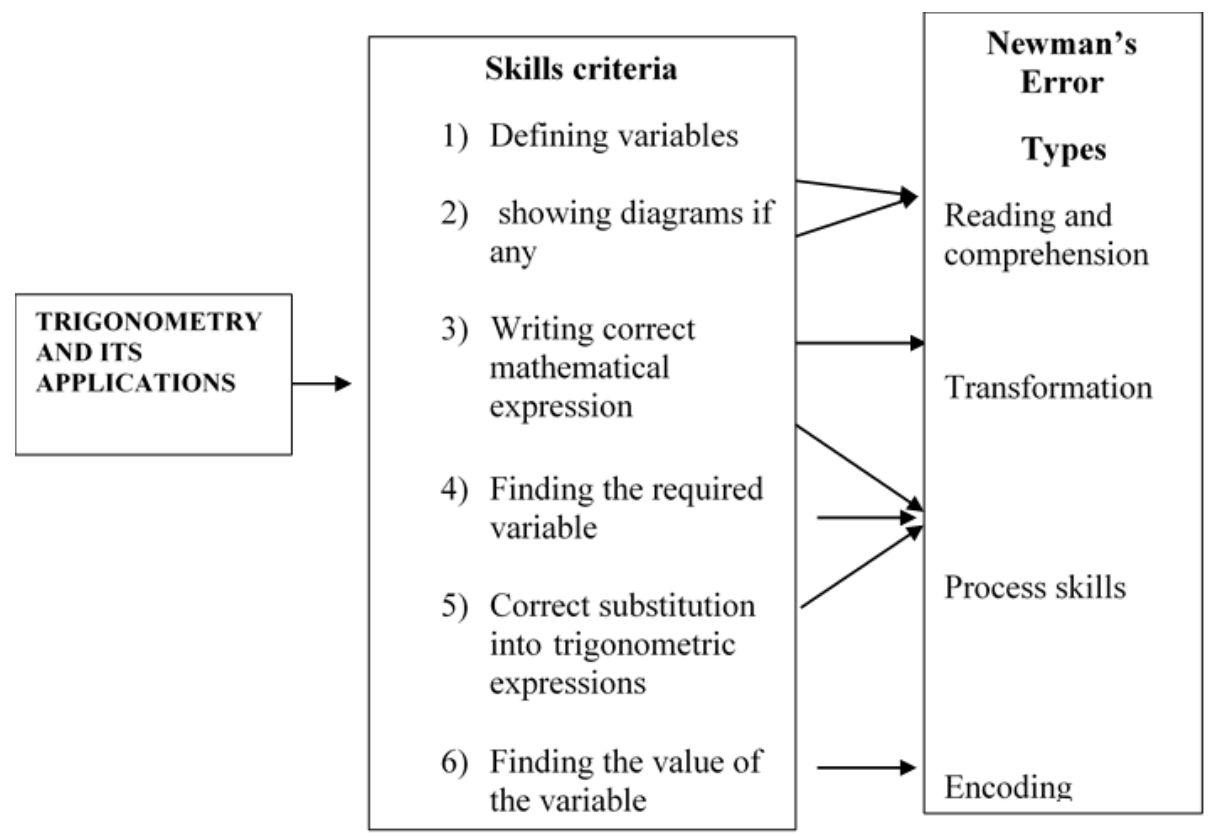

In solving mathematical problems involving Higher Order Thinking Skills (HOTS), Effandi (2010), opined that, Newman's Error Analysis Model has a hierarchy that categorizes types of error based on the levels of problem - solving ability of students. In the process of problem-solving. There are two factors that inhibit students ability to produce the correct answer, namely a) problems in language fluency and conceptual understanding (reading and comprehension) and b) problems in mathematical processing (transformation, process skills and encoding) (Prakitipong \& Nakamura, 2006). This clearly shows that students need to understand the meaning of the questions before going through the mathematical processing in order to produce the correct answers. Newman Error Analysis Model is widely implemented by researchers to determine the type of mistakes made by students in solving mathematical problems (Saleh et al., 2017).

Newman's research has also generated a large amount of evidence highlighting that far more children experience difficulty with the semantic structures, the vocabulary, and the symbolism of mathematics than with the standard algorithms as well as absence of links between the students' formal language and mathematical skills, and their personal worlds. Clements (1980) argued that mathematical modeling should be present whenever a learner attempts to solve a real-life problem or a mathematics word problem, however, this has not been frequent in classrooms.

\section{METHODOLOGY}

The main aim of this study was to explore students' errors in trigonometry pertaining to distance bearing problems, angle of elevation and depression. Quantitative research design was employed for this study. Quantitative research start and end with theory. This required knowledge of the theories and explanations of the phenomenon the researchers want to study and identify controversies or gaps in knowledge (Stockemer, 2019). These gaps then serve as point of reference for formulation of hypothesis or question. In this study, we formulate hypotenuse to test whether there's difference between girls and boys in committing errors in trigonometry problem solving. We also asked question to identify the errors displayed by students in solving trigonometry problems. 


\section{Study Area}

The Adansi South District is one of the twenty-seven (27) districts in the Ashanti Region of Ghana. The district capital is New Edubiase, which is about $92 \mathrm{~km}$ south of Kumasi on the Kumasi - Cape Coast trunk road. The district was created on 18th February, 2004 by a Legislative Instrument (LI 1752) through an Act of Parliament (Act 462, 1993). The creation of the district was based on the effort to decentralize government system, by bringing it closer to the doorstep of people. The study areas were selected because of the proximity to the researchers and easy accessibility to obtain the required data.

\section{Population}

The target population of the study comprise of Senior High Students in the Adansi South of Ghana. The district has two public Senior High Schools namely: New Edubiase Senior High School and Akrofuom Senior High School. There is no private Senior High School in the district. The form three students were selected because they have already studied trigonometry in form two based on the curriculum (Ministry of Education, 2010a, 2010b). The form two students were not selected because, during the time of data collection, they are yet to study trigonometry and therefore could not be considered. The accessible population was form three students of New Edubiase Senior High Students in the Adansi South District. The students grouping according to their respective courses are shown in Table 2.

Table 2. Form Three (3) Population of New Edubiase Senior High School

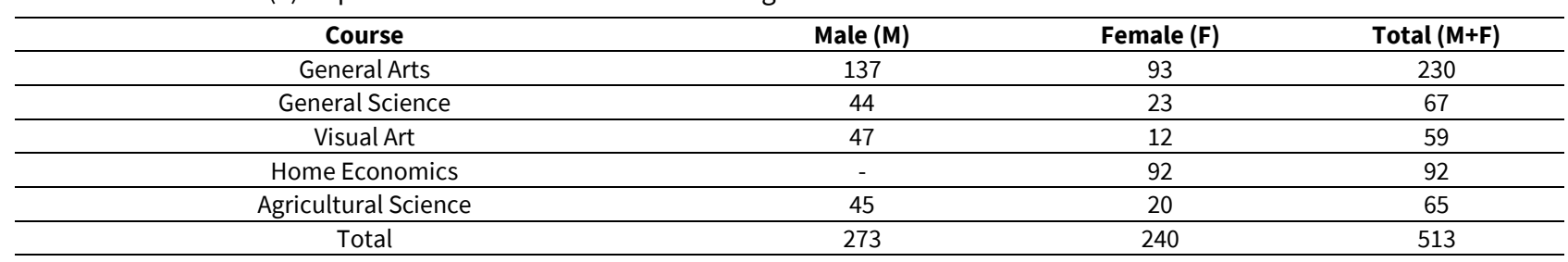

Source (New Edubiase Senior High School, 2018)

Out of the five hundred and thirteen (513) students, two hundred and thirty (230) students read General Arts, sixty- seven (67) read General science, visual arts a student population of fifty-nine (59), Home Economics and Agricultural Science have population of ninety-two (92), and sixty-five (65) students respectively.

\section{Sampling and Sampling Techniques}

A sampling is a process of selecting from a group or population to become the foundation for estimating and predicting the outcome of the population as well as to detect the unknown piece of information (Nayak \& Singh, 2015). Purposive sampling techniques was used in the selection of the New Edubiase Senior High School for the study. Purposive sampling was used because of the proximity of the school to the researchers. This is a group of individuals with the same characteristics as the target population and is trusted to provide the relevant data as it would be obtained from the whole population (De Vos, 2002). Nonprobability sampling is a technique used for selecting a sample from a population using specific characteristics needed by the researchers (Nayak \& Singh, 2015). Form three classes were purposively selected because the topic is within form two's mathematics syllabus for Ghanaian students. A total of ninety (90) students were sampled from the students' population of five hundred and thirteen (513). This forms eighteen percent (18\%) of the total population since this agrees with the work of Gorard (2001) who claimed a sampling fraction of between (10 - 20)\% of the population is acceptable. Therefore, sampling eighteen (18\%) present of the population is within $(10-20) \%$ which is enough for the study. Stratified sample technique was used in the sampling of the students for the study. According to Nayak and Singh (2015), a stratified sample is obtained by independently selecting a spate simple random sample from each population stratum. They added that a population can be divided into different groups, which may be based on some characteristic or variable like income of education. In this study, the sample size was divided into groups (strata). These groupings were created according to their course of study namely General Science, Visual Arts, Home Economics, Business, General Arts and Agricultural Science in the school. To ensure gender parity and representation, the gender population ratio of the schools was used to select the respondents for each school and each course. Computer randomized technique was used to select the respondents in each group (stratum) as shown in Table 3.

Table 3. Distribution of Gender based on Classes

\begin{tabular}{|c|c|c|c|}
\hline Course & Male (M) & Female (F) & Total (M+F) \\
\hline General Arts & 25 & 15 & 40 \\
\hline General Science & 7 & 4 & 11 \\
\hline Visual Art & 11 & 5 & 16 \\
\hline Home Economics & 0 & 14 & 14 \\
\hline Agricultural Science & 7 & 2 & 9 \\
\hline Total & 50 & 40 & 90 \\
\hline
\end{tabular}

\section{Trigonometry Achievement Test (TAT)}

The goals of the study formed the foundation from which the instrument was designed. The Trigonometry Achievement Test (TAT) was used as instrument in the collection of data. The test was used to find out if the students can identify basic trigonometry ratios and if they are able to use it to solve questions involving bearings, angle of elevations and depressions. The test was openended to allow students' present solutions to identify the errors they commit in trigonometry problem solving. The items were developed by the researchers because the assessment tool on angle of elevations, depressions, bearing problem in the literature appears to be scared. There are ten (10) items in the Trigonometry Achievement Test (TAT)). The first five questions are on the 
general knowledge of students in trigonometry. The ability of students to answer correctly the first five questions show the mastering of trigonometry and there can be able to apply it to solve questions on angles of elevations, depressions and bearing problems. The remaining of the five (5) questions were constructed from distance bearing problems, angle of elevation and depression. Items 2, 3, and 5 were scored four marks each whilst the rest (Items 1, 4, 6, 7, 8, 9, and 10) were scored out of five marks each. The test was used in identifying students' errors in trigonometry. The test instrument can be seen in Appendix A. The researchers consider the following criteria in the construction of the test items:

i. Facility level: not too easy neither too hard

ii. Variety: questions were selected to represent the different area of trigonometry in the syllabus to ensure a wide coverage of Senior High School syllabus, specifically bearings, angle of elevation and depression.

iii. Eliciting ideas: there were some consultation with experienced teachers and professional in the field on the test item used in the study.

\section{Validity and Reliability of the Research Instrument}

To ensure the validity of the instrument, the researchers consulted an expert after constructing the test items. This was done to validate the extent to which the items can measure what they are set out to measure (Fraekel \& Wallen, 2005). To ensure the reliability, a pilot study was conducted. The test items were pilot tested in one of the Dompoase Senior High Schools in the Adansi North of the Ashanti Region that fall within the same category of schools where the main study was conducted (Ministry of Education, 2014). This was done to identify the inconsistency in the test items and gives the researchers the opportunity to redesign and predict possible problems encountered in using the test items (Lancaster, Dodd, \& Williamson, 2004). Participants' scores from the pilot study were correlated using Cronbach alpha formula used in reliability testing to ensure the consistency of the instrument specifically on the final section of the SAQ. Cronbach alpha was used because it was "more efficient way of testing reliability" and was less time-consuming (Durrheim, 1999, p. 90). The value of the reliability coefficient was 0.708 and this value indicates a high degree of reliability of the items in the instrument (Fraekel \& Wallen, 2005).

\section{Data Collection Procedure}

Permission was sought from the Heads of the selected Senior High Schools to enable participation of students in the study. The researchers then met the participants and briefed them on the purpose of the study. The participants were assured of the confidentiality of all the information they would. To ensure anonymity participants name and identity were held. All the participants responded to the test at same time. This made measurement more accurate since all participants answered the same test items and marks were awarded according to the rubrics for scoring. The completed test items were collected and coded on the return for data entry and further analysis.

\section{Data Analysis}

A content analysis was carried out to identify the specific errors made by the students in solving trigonometry problem. Descriptive and inferential data analysis were used with the aid of a Statistical Product and Service Solutions (SPSS) version 21. The descriptive statistics together with modified Newman's model was used in an attempt to understand, interpret and classify the students' errors in solving trigonometry problems whilst the inferential statistics was used to generalize from the context of the research study itself to other settings or contexts (De Vos, 2002).

\section{Test for Normality Assumptions}

Before the independent sample t-tests was used, the researchers ensured that all the assumptions needed for samples $t$-test were met. The results of the assumptions are given below:

The normality assumption: Students' test scores (dependent variable) were normally distributed within each of the two groups (male and female groups). Lund (2012) argue that an assessment of the normality of data is a prerequisite for many statistical tests as normal data is an underlying assumption in parametric testing. The author stressed that there are two main methods of assessing normality and these are graphical and numerical. To determine whether the dependent variables (test scores) were normally distributed for each combination of the levels of the independent variables, test of Normality was employed. Here, the researchers used the Q-Q plot to test for the normality of the scores used for the analysis (see Figure 1). 


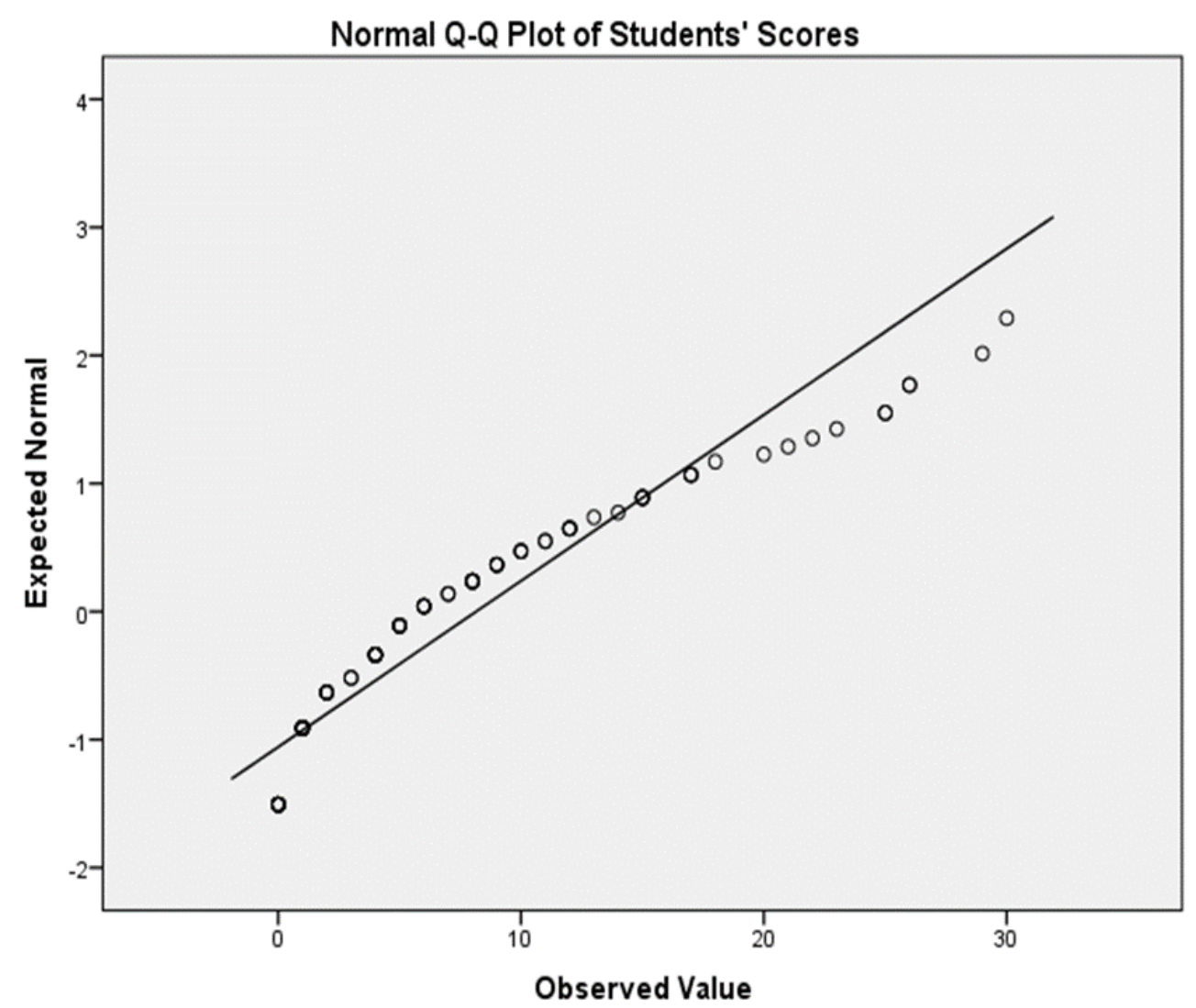

Figure 1. Normal Q-Q plot of Students' Test Scores

As can be seen in Figure 1, the results from the normal Q-Q plot of students' test scores (dependent variables) appear to be normally distributed for each of the categories in the independent variables. That is, very little departure from normality for the score variables, since most of the values were not far away from the straight line. Thus, the normality assumption was not violated.

Homogeneity of variance: Another assumption that the researchers deployed before using the independent sample t-test was the homogeneity of variance, that is, Levene's test. The test looked at whether there are any significant differences between group variances. If the $p$-value less than 0.05 then the researchers would have concluded that the variance across groups was significantly different or unequal. Therefore, the assumption of homogeneity of variance was also not violated.

Independence assumption: The data scores must be independent of each other (that is, scores of one of the participants are not analytically related to scores of the other participants). Here, the researchers also tested for the independence assumption and the scores of males and females were found to be independent of each other. In addition, an eta statistic squared was used to determine the magnitude of the difference (effect size) between the means of the scores. The criterion used for interpreting eta squared values are $0.2=$ small effect, $0.5=$ moderate effect and $0.80=$ large effect (Cohen, 1988).

\section{RESULTS}

To identify students' errors in solving problems related to trigonometry, the modified procedure of Newman Error Hierarchical Model (NEHM) was employed as conceptual model. The independent sample t-test was used to compare the means of the male and the female students' test scores to figure out if they statistically significantly differ. The next section examine SHS students' errors made when solving problems related to trigonometry.

\section{Students' Error in Solving Trigonometry Problems}

In this study, errors committed by students from the outcome of the written test were based on the modified procedure of Newman Error Hierarchical Model comprises of Reading and Comprehension, Transformation, Process skills and Encoding errors. Based on the above skills criteria, the test was marked and the errors committed among students were identified. Table 4 shows the distribution of students' attempting and making errors in solving problems related to trigonometry. 
Table 4. Distribution of Students' Error in Solving Trigonometry Problems

\begin{tabular}{|c|c|c|c|c|c|}
\hline \multirow{2}{*}{ Item } & \multirow{2}{*}{ Level } & \multicolumn{2}{|c|}{ Attempted $(\mathrm{N}=90)$} & \multicolumn{2}{|c|}{ Error $(\mathrm{N}=90)$} \\
\hline & & $\mathbf{N}$ & $\%$ & $\mathbf{N}$ & $\%$ \\
\hline \multirow{4}{*}{ Item 1} & Reading and Comprehension & 73 & 81.1 & 38 & 42.2 \\
\hline & Transformation & 73 & 81.1 & 44 & 48.9 \\
\hline & Processing Skills & 70 & 77.8 & 44 & 48.9 \\
\hline & Encoding & 57 & 63.3 & 34 & 37.8 \\
\hline \multirow{4}{*}{ Item 2} & Reading and Comprehension & 82 & 91.1 & 59 & 65.6 \\
\hline & Transformation & 79 & 87.8 & 59 & 65.6 \\
\hline & Processing Skills & 76 & 84.4 & 56 & 62.2 \\
\hline & Encoding & 77 & 85.6 & 56 & 62.2 \\
\hline \multirow{4}{*}{ Item 3} & Reading and Comprehension & 77 & 85.6 & 15 & 16.7 \\
\hline & Transformation & 73 & 81.1 & 32 & 35.6 \\
\hline & Processing Skills & 70 & 77.8 & 55 & 61.1 \\
\hline & Encoding & 69 & 76.7 & 67 & 74.4 \\
\hline \multirow{4}{*}{ Item 4} & Reading and Comprehension & 71 & 78.9 & 45 & 50.0 \\
\hline & Transformation & 70 & 77.8 & 50 & 55.6 \\
\hline & Processing Skills & 65 & 72.2 & 49 & 54.4 \\
\hline & Encoding & 52 & 57.8 & 39 & 43.3 \\
\hline \multirow{4}{*}{ Item 5} & Reading and Comprehension & 80 & 88.9 & 38 & 42.2 \\
\hline & Transformation & 78 & 86.7 & 43 & 47.8 \\
\hline & Processing Skills & 77 & 85.6 & 42 & 46.7 \\
\hline & Encoding & 71 & 78.9 & 45 & 50.0 \\
\hline \multirow{4}{*}{ Item 6} & Reading and Comprehension & 63 & 70.0 & 42 & 46.7 \\
\hline & Transformation & 58 & 64.4 & 43 & 47.8 \\
\hline & Processing Skills & 46 & 51.1 & 41 & 45.6 \\
\hline & Encoding & 43 & 47.8 & 41 & 45.6 \\
\hline \multirow{4}{*}{ Item 7} & Reading and Comprehension & 58 & 64.4 & 38 & 42.2 \\
\hline & Transformation & 50 & 55.6 & 39 & 43.3 \\
\hline & Processing Skills & 46 & 51.1 & 38 & 42.2 \\
\hline & Encoding & 45 & 50.0 & 38 & 42.2 \\
\hline \multirow{4}{*}{ Item 8} & Reading and Comprehension & 45 & 50.0 & 36 & 40.0 \\
\hline & Transformation & 24 & 26.7 & 22 & 24.4 \\
\hline & Processing Skills & 15 & 16.7 & 14 & 15.6 \\
\hline & Encoding & 14 & 15.6 & 13 & 14.4 \\
\hline \multirow{4}{*}{ Item 9} & Reading and Comprehension & 44 & 48.9 & 16 & 17.8 \\
\hline & Transformation & 31 & 34.4 & 28 & 31.1 \\
\hline & Processing Skills & 29 & 32.2 & 29 & 32.2 \\
\hline & Encoding & 28 & 31.1 & 28 & 31.1 \\
\hline \multirow{4}{*}{ Item 10} & Reading and Comprehension & 30 & 33.3 & 13 & 14.4 \\
\hline & Transformation & 22 & 24.4 & 11 & 12.2 \\
\hline & Processing Skills & 19 & 21.1 & 10 & 11.1 \\
\hline & Encoding & 19 & 21.1 & 12 & 13.3 \\
\hline
\end{tabular}

From Table 4, it is clear that majority of the students attempted the reading and comprehension level, but few were able to actually read and comprehend meaningfully. For instance, $81.1 \%(\mathrm{~N}=73)$ attempted to read and comprehend in the first question (Item 1) but 38.9\% ( $\mathrm{N}=35)$ were successful (that is, 42.2\%, N=38 made errors). Moreover, majority of the students attempted the transformation level (that is, writing correct mathematical expression) again, most of them made errors. For example, $64.4 \%$ who attempted to transform after attempting to read and comprehend, $47.8 \%$ out of the $64.4 \%$ made errors thus, only $16.6 \%$ were able to transform correctly. It could be concluded from Table 4 that majority of the errors emanated from processing skills. For instance, in items 8,9 , and $10,16.7 \%, 32.2 \%$, and $21.1 \%$ respectively were able to attempt the processing skills and $15.6 \%, 32.2 \%$, and $11.1 \%$ committed processing skills errors. It could also be seen from Table 4 that a substantial number of the students were not able to attain the encoding level thus getting the answer correctly. In this study, most of the students made several errors. Some of the errors made by the students are shown in the exhibits below. 


\section{Exhibit 1}

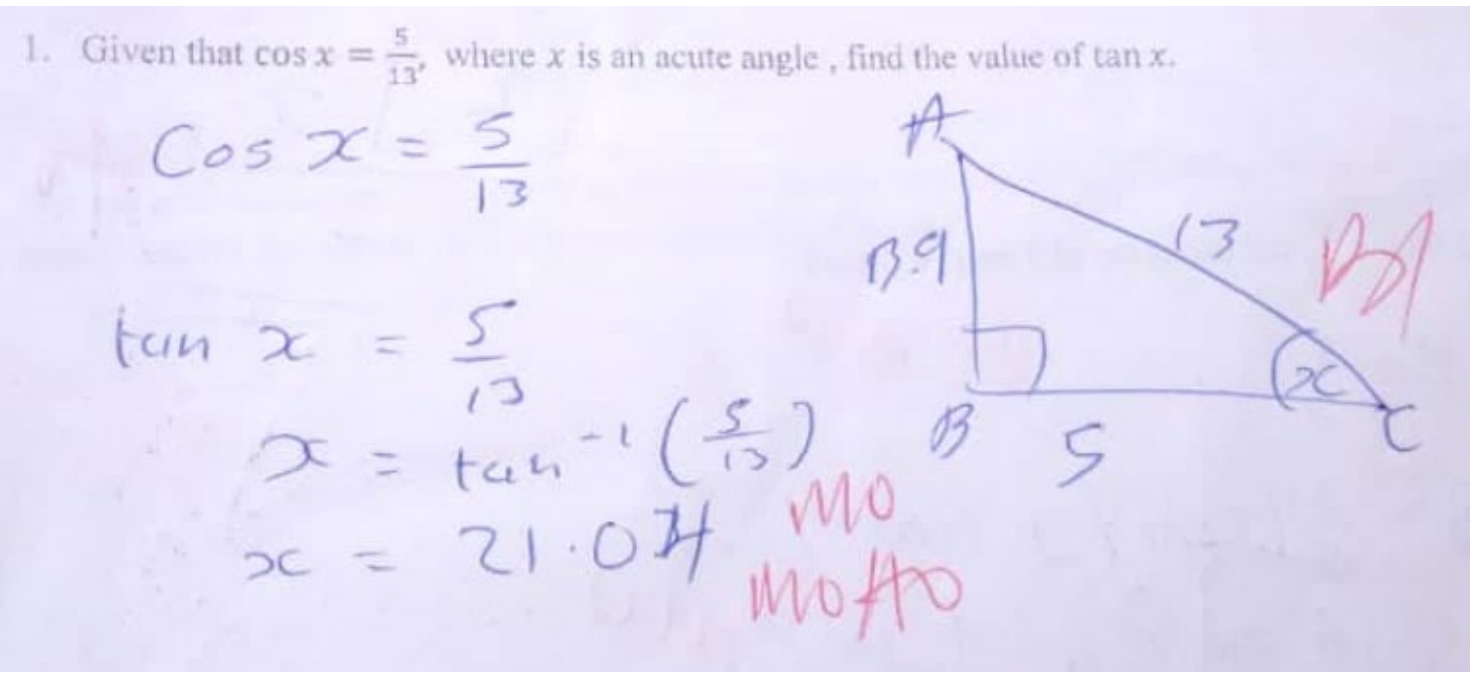

As demonstrated in Exhibit 1, although most of the students were able to read and comprehend by identifying the correct given sides, they were not able to write mathematical statements by applying the pythagoras theroem in other to procced to the next level. This shows that the students can comprehend but may not transformed the problem to mathematical statement.

In Exhibit 2, instead of the student to apply the idea of complementary angle that is $\sin \alpha=\cos \beta$, if $\alpha+\beta=90$, (the use of distributive property in an algebraic expression familiarises students) with $\cos (y+50)=\cos y+50 \cos$ which is mathematically wrong but instead goes like $\cos \left(y+50^{\circ}\right)=\operatorname{cosycos} 50^{\circ}-\operatorname{siny} \sin 50^{\circ}$. Exhibit 2 shows sample of what the students did.

\section{Exhibit 2}

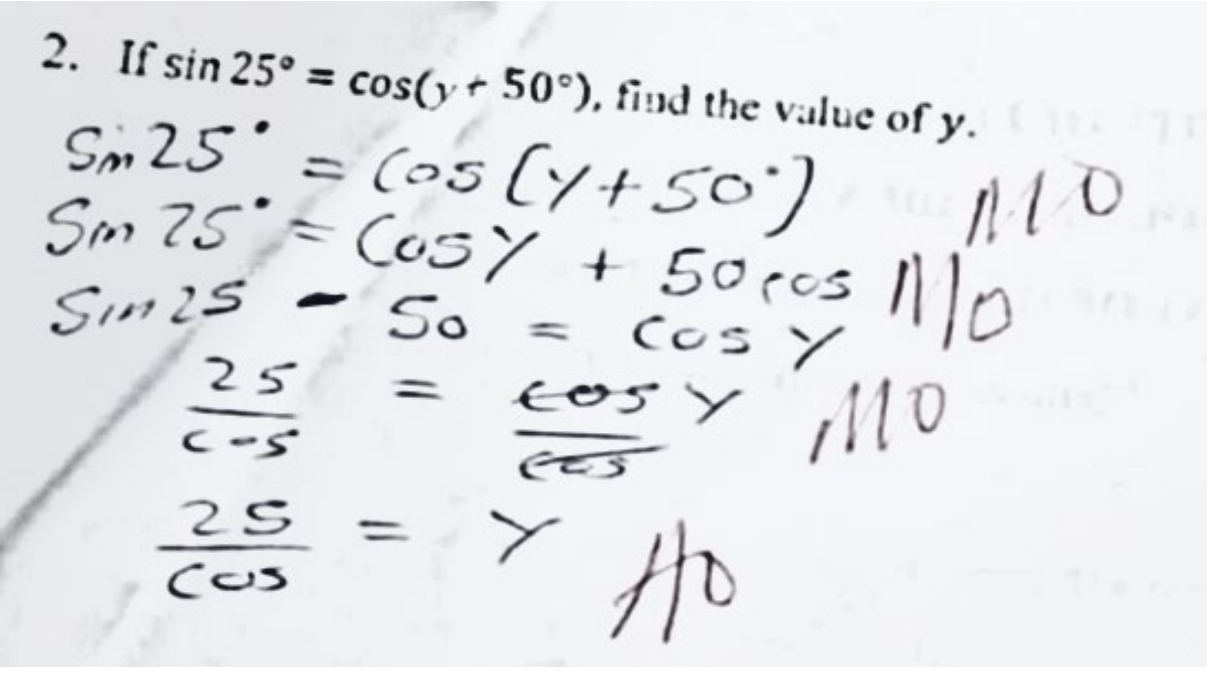

In exhibit 3, the difficulty of students in transforming $\sin Y$ to $\cos Y$ and substituting the trigonometric expression was not different here. Again, the student could not process his or her skills well let alone arrive at the encoding level. Exhibit 3 presents sample of how the students solve the problem in item 4. 


\section{Exhibit 3}

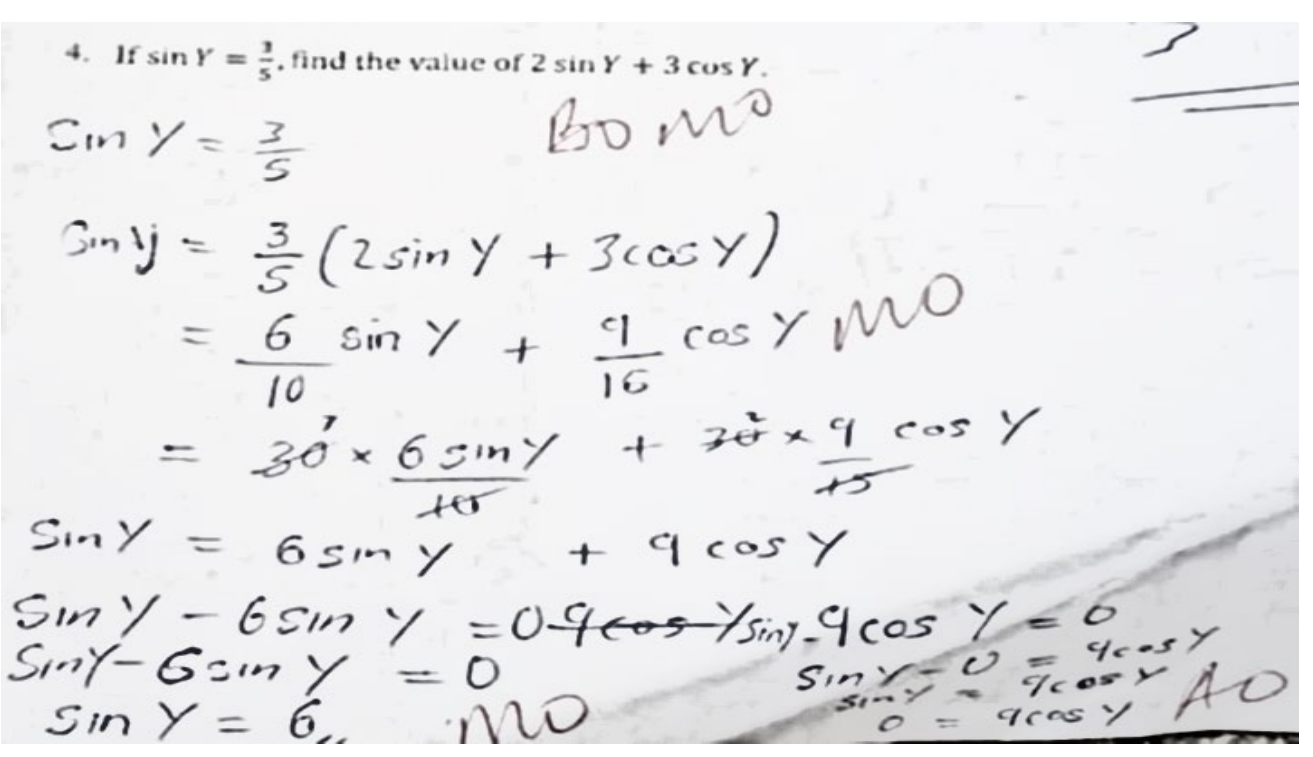

Consequently, in Exhibit 4, instead of the student to apply the trigonometric ratio that is $\sin x=\frac{3 \mathrm{~cm}}{5 \mathrm{~cm}}$ and take the $\arcsin \frac{3 \mathrm{~cm}}{5 \mathrm{~cm}}$ to simply make $x$ the subject as demanded in the question, it seemed the student was trying to apply the Pythagoras theorem to answer this question which was not required here. This shows the students could not absolutely read and comprehend. Exhibits 4 and 5 presents sample of how the students solve the problem.

\section{Exhibit 4}

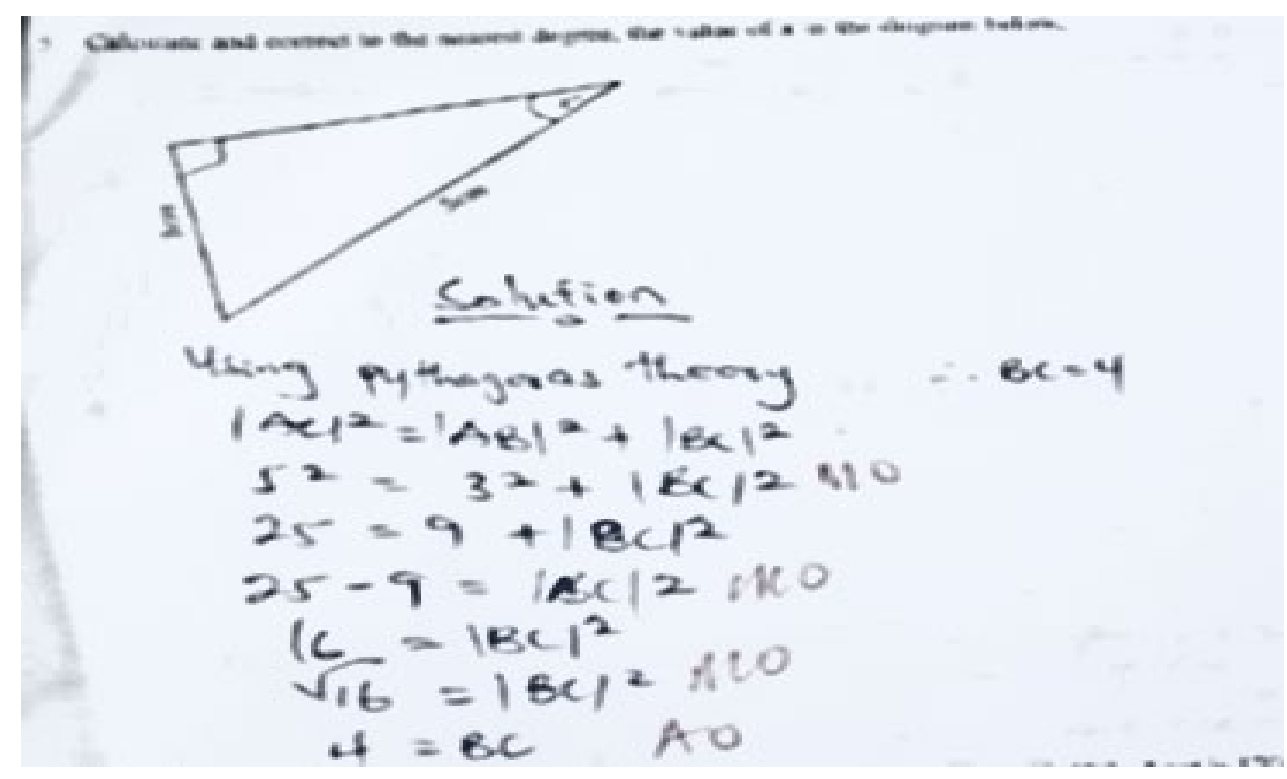




\section{Exhibit 5}

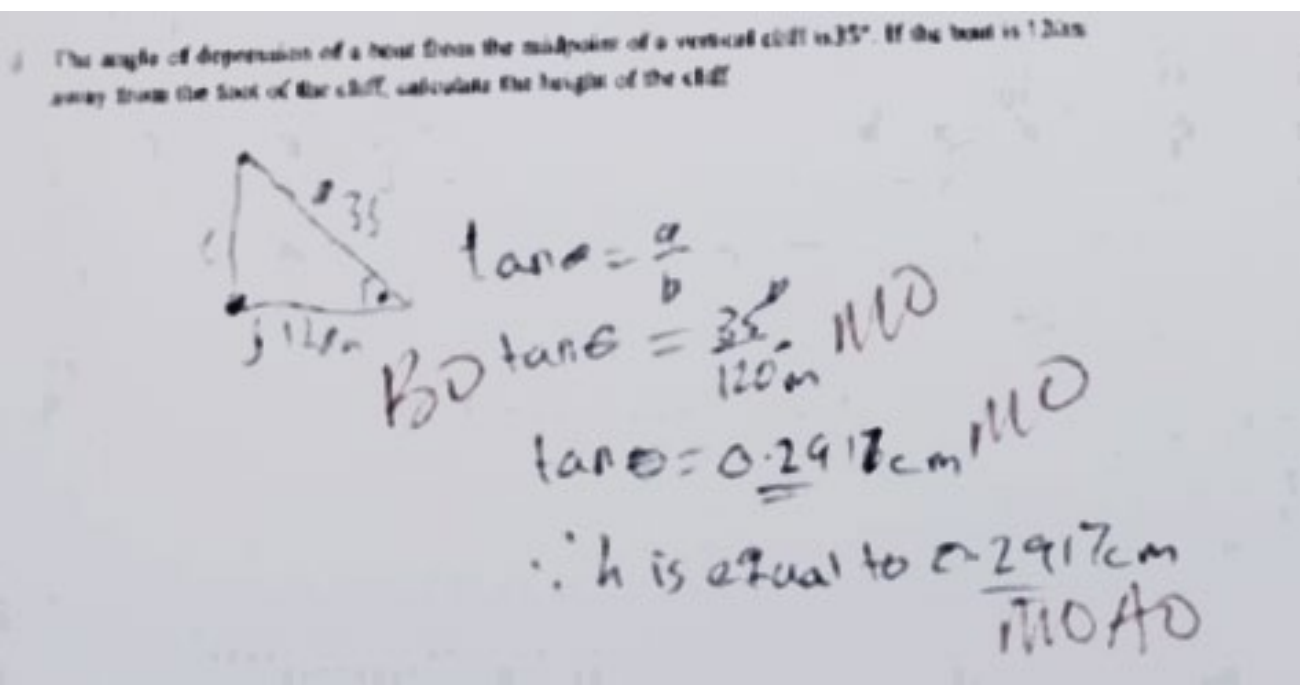

Inference from exhibit 5 is that, students have a very low understanding when it comes to solving problems related to trigonometry especially the application of trigonometry. As demonstrated in Exhibit 5 many of the students were unable to define the variables not to even write the mathematical statements correctly thus made errors in the process. In Exhibit 5 for instance, students were required to read and comprehend the problem. It is not surprising large proportion (46.7\%) out of the $70 \%$ who attempted the question in item 6 made reading and comprehension errors (see Table 4). However, $47.8 \%$ out of $64.4 \%$ who proceeded to attain to transformation level also committed errors. A substantial proportion (45.6\%) out of 51.1\% could not process their skills correctly. During the encoding level thus students arriving at the correct answer, the percentage (45.6\%) number of students who made errors in the processing skills level all could not arrive at the correct answer. This indicates that majority of the students had difficulties in solving trigonometry problems.

\section{Gender Differences in Errors on Trigonometry Problem Solving}

To determine if there is any significant difference among male and female SHS students in their level of committing errors in solving problems related to trigonometry, descriptive statistics (mean, standard deviation, minimum and maximum scores) for the test scores among the male and female students were calculated. The results of the analysis are summarized in Tables 5.

Table 5. Descriptive statistics on test scores among the male and female students

\begin{tabular}{cccccc}
\hline Group & N & Minimum & Maximum & Mean & Std. Deviation \\
\hline Male & 50 & 0 & 30 & 9.72 & 8.588 \\
\hline Female & 40 & 0 & 25 & 6.20 & 5.992 \\
\hline
\end{tabular}

Table 5 shows the mean score of the male students $(M=9.72, S D=8.588)$ was greater than that of the female students $(M=6.20$, $\mathrm{SD}=5.992)$. This indicates that the male students performed better than their female counterparts. This is an indication that the female students committed more errors than their male counterparts. To test whether the difference in mean scores between the male and female students was statistically significant, an independent-samples t-test was performed at $5 \%$ level of significance. Table 6 presents the results of the independent samples t-test.

Table 6. Independent sample t-test results showing gender differences in errors on trigonometry

\begin{tabular}{|c|c|c|c|c|c|c|c|}
\hline Group & $N$ & Mean & Std. Deviation & t-value & $D f$ & P-value & Eta Square \\
\hline Male & 50 & 9.72 & 8.588 & \multirow{2}{*}{2.198} & 89 & \multirow{2}{*}{0.031} & \multirow{2}{*}{0.41} \\
\hline Female & 40 & 6.20 & 5.992 & & & & \\
\hline
\end{tabular}

Independent samples t-test statistic was conducted on gender differences in mean among male and female students to test the null hypotenuse. The results of the independent samples t-test (Table 6) of groups' differences in mean among male and female students indicated that there was a significant difference in their mean scores at $t(89)=2.198, p<0.05$. Therefore, the null hypothesis that "there is no statistical significant difference among male and female SHS students in their level of committing errors in solving problems related to trigonometry" was rejected at a 95\% confidence interval. Hence, it can be argued statistically that the female students' level of committing errors in solving problems related to trigonometry was significantly higher than their male counterparts. In addition, the eta square statistics (0.41) discovered that the difference between female and male students' level of committing errors when solving trigonometry problems is small (Cohen, 1988).

\section{DISCUSSION}

The findings indicates that majority of students attained the reading and comprehensions level indicating that, they have been introduced to the topic trigonometry, this means students have little problems in reading the items but the comprehension levels of the students are very low. This finding is in agreement with the results of many studies. For example, in Newman studies carried out in schools the proportion of errors first occurring at the Comprehension and Transformation' stages have been large (Marinas \& Clements, 1990; Singhatat, 1991). The authors found that Reading (Decoding) errors accounted for less than 5 percent of initial 
errors and the same was true for Process Skills errors, mostly associated with standard numerical operations. Thus, studies regularly reported that approximately 70 percent of errors made by Year 7 students on typical mathematics questions were at the Comprehension or Transformation levels.

Also, the finding of this study agrees with earlier findings in the research of Mensah (2017), which found that the most frequent errors made by student in using formulae and right angled - triangle in solving trigonometric ratios occurs mostly at process skills error, transformation errors and comprehension errors levels. However, majority of students can read the items correctly hover the understanding of the items was the students problem at the comprehensions levels and this concurs with the findings of Norasiah (2002) in which problematic students failed to translate mathematical problems into mathematical form and also having problem in understanding the special terms in mathematics. Additionally, students encounter problems $\operatorname{such}$ as $\sin (x+30)$ they expand $\sin (x+30)$ as $\sin x+\sin 30$ as if its algebraic expressions. Also, most students applied Pythagoras theorem wrongly. Thus, questions with a triangle which does not have any angle $90^{\circ}$, students still used the Pythagoras theorem. This finding is in line with the findings of Skane and Graeber (1993) who claim that some errors displayed by students in the content of algebra, logarithms, exponents and trigonometry are attributed to the distributive law. They further suggest that traditional instruction is not a sufficient strategy to remediate distributive law errors for some students.

Additionally, the finding from this study that female students' level of committing errors in solving problems related to trigonometry was significantly higher than their male counterparts is consonant with the findings of (Tommaso et al., 2016). The effect size revealed that the difference between the means of male and female students in the levels of committing errors in solving of trigonometry problem was small. This finding, however, run counter to those of Brown and Kanyongo (2010) who find gender differential in mathematics performance in favour of girls. Shelley (2016) recommended that, support should be provided to girls as remedial support to enable girls "catch up" with boys. Provisions should be made in all programs, training, education materials and curriculum content for gender mainstreaming and strategic planning to ensure that girls' needs are met in mathematics. Girls should be provided with support for time management in order to maximize efficiency with respect to coping with domestic workloads and educational demands and career counselors who are knowledgeable about mathematics - related careers and female role models are needed to encourage and motivate girls to pursue higher level mathematics. Antecol and Ozbelik (2015) posit three ways in which a weaker test scores for girls in mathematics could arise. First, teachers without, strong subject backgrounds may adopt a more mechanical teaching style that is fine for male students but may not be good for female students. Alternatively, female teachers may teach STEM subjects just as well as male teachers, but female students may respond more positively (negatively) to a male (female) teacher at certain ages.

\section{CONCLUSION AND IMPLICATION}

Based on the findings, it is concluded that majority of the students have little or poor knowledge in tackling trigonometry problems even though it's a topic they have learnt in the previous year. The errors in this study were identified using modified procedure of Newman Error Hierarchical Model, which are Reading and Comprehension, Transformation, Process skills and Encoding. Another notable finding made was that most of the students made several errors. Findings from the results show that of the mean percentage (69.2\%) who attempted the Reading and Comprehension level, $37.8 \%$ committed errors. However, an extensive proportion (45.6\%) out of $51.1 \%$ could not process their skills correctly to reach encoding error stage (inability to write the required answer to the question).

Independent samples t-test (see Table 6) of groups' differences in means among male and female students indicated that there was a significant difference in their mean scores at $t(89)=2.198, p<.05$. Thus, female students' level of committing errors in solving problems related to trigonometry was significantly higher than their male counterparts. The occurrence of these errors may be as a result of the teaching strategies used by teachers. Learners who receive high-quality instruction in mathematics experience greater and more persistent achievement than their counterparts who receive lower-quality instruction in mathematics (Rivkin, Hanushek, \& Kain, 2005).

Teaching approach need to focus on students' needs and curricular requirements. Student errors in mathematics classrooms required a specialized activity of formative assessment, which relies on teachers' deep knowledge of content, and requires teachers" professional judgment on how to respond to learners' needs when teaching in a particular content (Sapire et al., 2016). The errors commited can be addressed through practical teaching and the use of technology in teaching trigonometry (e.g geogebra). Zengin, Furkan, and Kutluka (2012) recommend dynamic mathematics software geogebra for teaching of trigonometry for understanding of students. The interactive computer program (mathematical programs including matlab, maple, Geogebra and Geomter's Sketchpad) is very useful, attractive and powerful device in the proces of teaching and leaning mathematics, especially for understanding concepts in mathematics (Lumbantobing, 2018).

\section{SUGGESTIONS FOR AREAS OF FURTHER RESEARCH}

Based on the findings, the following areas are recommended for further research:

- The study covered only one Senior High School in the Ashanti Region of Ghana. Other study could also be conducted so that more Senior High schools could be used to give a wider view on the errors encountered in solving problems related to trigonometry. 
- Other study should be conducted on the use of manipulative approach in teaching trigonometry and observes its effect on minimizing students' errors in solving problems related to trigonometry.

Author contributions: All authors have sufficiently contributed to the study, and agreed with the results and conclusions.

Funding: No funding source is reported for this study.

Declaration of interest: No conflict of interest is declared by authors.

\section{REFERENCES}

Antecol, E. H., \& Ozbeklik, S. (2015). The effect of teacher gender on students achievement in primary school. Journal of Labor Economics, 33(1), 63-89. https://doi.org/10.1086/677391

Antoro, R. J., Samosir, R. S., Kavling, P. S., \& Indonesia, J. E. (2015). Trigonometry learning system with interactive multimedia for senior high school class XI. The Second International Conference on Computer Science, Computer Engineering and Education Technology (pp. 12-16). Malaysia: The Society of Digital Information and Wireless Communication (SDIWC) USA. https://doi.org/10.1145/1655925.1656042

Barlow, A. T., Watson, L. A., Tessema, A. A., Lischka, A. E., \& Strayer, J. F. (2018, April). Carefully select and leverage student errors for whole - class discussion to benefit the learning of all. Teaching children mathematiccs, 24(6), $384-391$. https://doi.org/10.5951/teacchilmath.24.6.0384

Brijlall, D. (2014). Exploring the pedagogical content knowledge for teaching probability in middle school: A South Africa case study. Internal Journal of Education and Science, 7(3), 719-726.

Brown, L. I., \& Kanyongo, G. Y. (2010). Gender and differences in mathematics performance in Trinidad and Tobago examining affective factors. International Electronic Journal of Mathematics Education, 5(3), $113-130$. https://www.researchgate.net/publication/285943823

Clements, M. A. (1980). Analyzing childrend's errors on written mathematical task. Educational Studies in Mathematics, 1-21.

Cohen, J. (1988). Statistical power analysis for the behavioural science (2nd Ed.) Lawrence Erlbaum.

De Vos, A. S. (2002). Research at grass roots: For the social sciences and human services professions. Van Schaik Publisher.

Debra, S. L. (2017). Gender, self-concept and Mathematics and Science performance of South Africa Grade 9 students. Bereau for Economic Research, 1-48.

Durkheim, E. K. (1999). Quantitative measurement. Applied Method for the Social Sciences, 72-95.

Effandi, Z., Chin, L. C., \& Daud, Y. (2010, 30 March 2010). Analysis of students' error in learning quadratic equations. international Education Studies, 6(2), 272-275. https://doi.org/10.3844/jssp.2010.272.275

Fanning, J. D. (2016). Students responses to instruction in rational trigonometry. Journal of Mathematics Education in Science and Technology, 39(7), 857-878.

Fi, D. C. (2003). Preservice secondary school mathematics teachers' knowledge of trigonometry: subject matter conttent knowledge, pedagogical content knowledge and envisioned pedagogy. lowa Research Online, 1-331.

Forgasz, H. J. (2015). Gender and Mathematics in Australia: A downward trajectory. The Proceedings of the 12th International Congress on mathematics education (pp. 156-161). Australia: Monash University. https://doi.org/10.1007/978-3-319-126883_12

Fraekel, J. R., \& Wallen, N. E. (2005). How to design and evaluate research in education. Jossey.

Fraenkel, J. R., \& Wallen, N. E. (2000). How to design and evaluate research in education (5th Ed.). McGraw-Hill Publishing Co.

Gaisman, M. T. (2015). Gender and mathematics education in Mexico. The proceedings of the 12th International Congress on Mathematics Education (pp. 151-153). Monash University. https://doi.org/10.1007/978-3-319-12688-3_12

Gorard, S. (2001). Quantitative methods of in educational research. Journal of Sociology of Education, 42(3), $309-321$. https://doi.org/10.15408/ijee.v5i2.9532

Grant, C., \& Osanloo, A. (2014). Understanding, selecting, and integrating a theoreticcal framework in dessertaqtion research: creating the blueprint for our "House". Admistrative Issues Journal, 12-26. https://doi.org/10.5929/2014.4.2.9

Gur, H. (2009). Trigonometry learning. New Horizons, 67-80.

Kissane, B., \& Kemp, M. (2009). Teaching and learning trigonometry with technology. 14th Asian Technology Conference in Mathematics (pp. 17-21). Beijing Normal University.

Kissane, B., \& Kemp, M. (2010). Teaching and Learning Trigonometry with Technology. ResearchGate, 1-10.

Lai, C.-F. (2006). Error analysis in mathamtics. Behavioral research and teaching. http://brt.uoregon.edu

Lancaster, G., Dodd, S., \& Williamson, P. R. (2004). Design and analysis of pilot studies: Recommendations for goof practice. Journal of Evaluation in Clinical Practice, 10(2), 307-312. https://doi.org/10.1111/j..2002.384.doc.x

Leder, G. (2015). Gender and mathematics education revisited. The Processings of the 12th International Congress on Mathematics Education (pp. 145-146). Monash University. https://doi.org/10.1007/978-3-319-12688-3_12

Lumbantobing, H. (2018). The effect of interactive computer program on students accomplishment in teaching trigonometry. International Journal of Sciences: Basic and Applied Research (IJSBAR), 38-48. 
Lund, T. (2012). Combining qualitative approach: Some argument for mixed methods research. Scandinavian Journal for Mixed Method Research, 56(2), 155-165. https://doi.org/10.1080/00313831.2011.568674

Marinas, F. N., \& Clements, M. A. (1990). Understanding the problem: A prerequisite to problem solving in mathematics. Journal of Science and Mathemataics Education in South Eaast Asia, 13(1), 14-20.

Mensah, J. K. (2017). Ghanaian senior high school students' error in learning of trigonometry. International Journal of Environmental \& Science Education, 1709-1717.

Ministry of Education. (2010a). Teaching syllabus for core mathematics (Senior High School, 1-3). Accra: Ministry of Education.

Ministry of Education. (2010b). Teaching syllabus for elective mathematics (Senior High School, 1-3). Accra: Ministry of Education.

Ministry of Education. (2014). Secondary Education Improvement Project (SEIP) project implementation manual. Accra: Ministry of Education.

Muzangwa, J., \& Chifamba, P. (2012). Analysis of errors and miscocnetpions in the learning of calculus by undergraduate students. Acta Dictactica Napocensia, 5(2), 1-19.

Nayak, J. K., \& Singh, P. (2015). Fundamentals of research methodology. New Delhi (India): SSDN Publishers and Distributions.

Newman, A. M. (1977). Analysis of sixth - grade pupils' errors on written mathematical tasks. Victorian: Institute for Educational Research Bulletin, 31-43.

Norasiah, A. (2002). Error type diagonsis in learning simultaneous equations (Unpublished master of education research project), University of Kebangsaan, Malaysia.

Prakitipong, N., \& Nakamura, S. (2006). Analysis of mathematics performance of grade five students in Thailand using Newmans procedure. Journal of International Cooperation in Education, 9(1), 111-122. https://doi.org/0.1016/j.sbspro.2010.12.036

Rivkin, S. G., Hanushek, E. A., \& Kain, J. F. (2005). Teacher, school and academic achievement. Econometrica, 73(2), 417-458. https://doi.org/10.1111/j.1468-0262.2005.00584.x

Rushton, S. J. (2018). Teaching and learning mathematics through error analysis. Journal of Cheminformatics, 3(4), 1-12. https://doi.org/10.1186/S40928-0009-Y

Saavedra, R., \& Garcia Belaude, S. (2010). Building educators awareness and knowledge of strategies to promote equity in the math classroom. APEC Conference on Replicating Exemplary Practices in Mathematics Education. Thailand.

Saleh, Y. K., As'ari, D. I., \& Abdur, R. (2017). Error Analysis solving problems analogies by Newman procedure using analogical reasoning. International Journal of Humanities of Social Sciences, 9(1), 17-26.

Sapire, I., Shalem, Y., Wilson-Thompson, B., \& Paulsen, R. (2016). Engaging with learners' errors when teaching mathematics. Pythagoras, 37(1), 331-353. https://doi.org/10.4102/pythagoras.v37i1.331

Sarwadi, H. H., \& Shahrill, M. (2014). understanding students' mathematical errors and misconceptions: The case of year 11 repeating students. International Scientific Publications and consulting services, 1-10. https://doi.org/10.5899/2014/metr00051

Shelley, J. (2016). Gender isssues in mathematics education in Tanzania. ResearchGate, 1-20.

Singhatat, N. (1991). Analysis of mathematics errors of lower secondary pupils in solving word problems. SEAMEO-RECSAM.

Skane, M. E., \& Graeber, A. O. (1993). A conceptual change model implemented with college students: distributive law misconceptions. Third International Coference on Misconcepttions in Science and Mathematics, (pp. 16-25). Ithaca.

Stockemer, D. (2019). Quantitative Methods for the Social Sciences. Cham, Switzerland: Springer International Publishing AG. https://doi.org/10.1007/978-3-319-99118-4

Unal, M. (2017). Preferences of teaching methods and techniques in mathematics with reasons. Universal Journal of Educational Research, 5(2), 194-202.

Usman, H. M., \& Muhammed, M. H. (2017). Analysis of Students' error in learning of trigonometry among seniorsecondary school students in Zaria Metropolis, Nigeria. IOSR Journal of Mathematics, 13(2), 1-4. https://doi.org/10.9790/5728-1302040104

Welber, K. (2008). Teaching trigonometric functions: lessons learned from research. Mathematics Teachers, $102(2), 144-150$. https://doi.org/10.5951/MT.102.2.0144

Wilderger, N. J. (2007). A rational apporach to trigonometry. Math Horizons, 15(2), 16-20. https://doi.org/10.13140/RG.2.1.1280.6488

Zengin, Y., Furkan, H., \& Kutluka, T. (2012). The effect of dynamic mathematics software geogebra on student achievemen in teaching trigonometry. Procedia-Social and Behavioral Sciences, 183-187. 


\section{APPENDIX A}

\section{Trigonometry Achievement Test}

\section{INSTRUCTIONS:}

i. Your performance in this test will have no bearing on your grades or evaluation in the subject.

ii. This assessment is for research purpose to improve teaching and learning of trigonometry.

iii. You are required to answer all questions honestly on the paper provided.

iv. Do and leave all workings or rough work on the paper.

Student's registered number. Time allowed: 1:30 hours

Sex:. ..age. class

1. Given that $\cos x=\frac{5}{13^{\prime}}$, where $x$ is an acute angle, find the value of $\tan x$.

2. If $\sin 25^{\circ}=\cos \left(y+50^{\circ}\right)$, find the value of $y$.

3. Given that $\theta=60^{\circ}$ and $\beta=30^{\circ}$, evaluate $\frac{(\sin \beta+2 \cos \theta)}{\cos \beta}$, leaving your answer in surd form.

4. If $\sin Y=\frac{3}{5}$, find the value of $2 \sin Y+3 \cos Y$

5. Calculate and correct to the nearest degree, the value of $x$ in the diagram below.

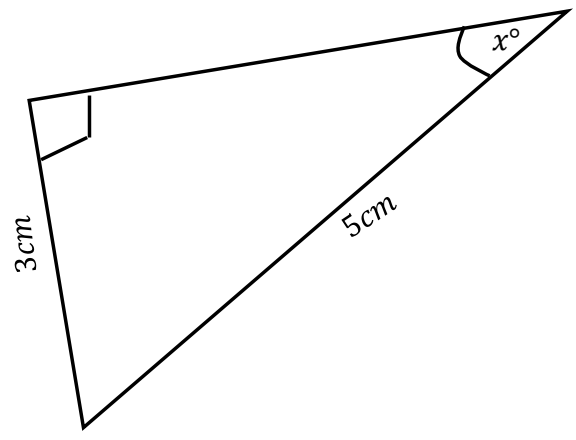

6. The angle of depression of a boat from the midpoint of a vertical cliff is $35^{\circ}$. If the boat is $120 \mathrm{~m}$ away from the foot of the cliff, calculate the height of the cliff.

7. The angle of elevation of the top of a flag pole is $42^{\circ}$ from a point $P$ which is 180 metres from the foot $B$ of the flag pole. $Q$ is a point on the same horizontal line BP such that $|B Q|=45$ metres. Calculate, correct to one decimal place, the angle of elevation of the flagpole from $\mathrm{Q}$.

8. The bearing of point $P$ from point $S, 10 \mathrm{~km}$ away is $025^{\circ}$. Another point $Q$ is $6 \mathrm{~km}$ from $S$ and on a bearing of $162^{\circ}$. Calculate the :
i. Distance PQ
ii. Bearing of $\mathrm{P}$ from $\mathrm{Q}$.

9. Using the diagram below find, correct to one decimal place

i. The distance between $\mathrm{R}$ and $\mathrm{Q}$.

ii. The bearing of $\mathrm{R}$ from $\mathrm{Q}$.

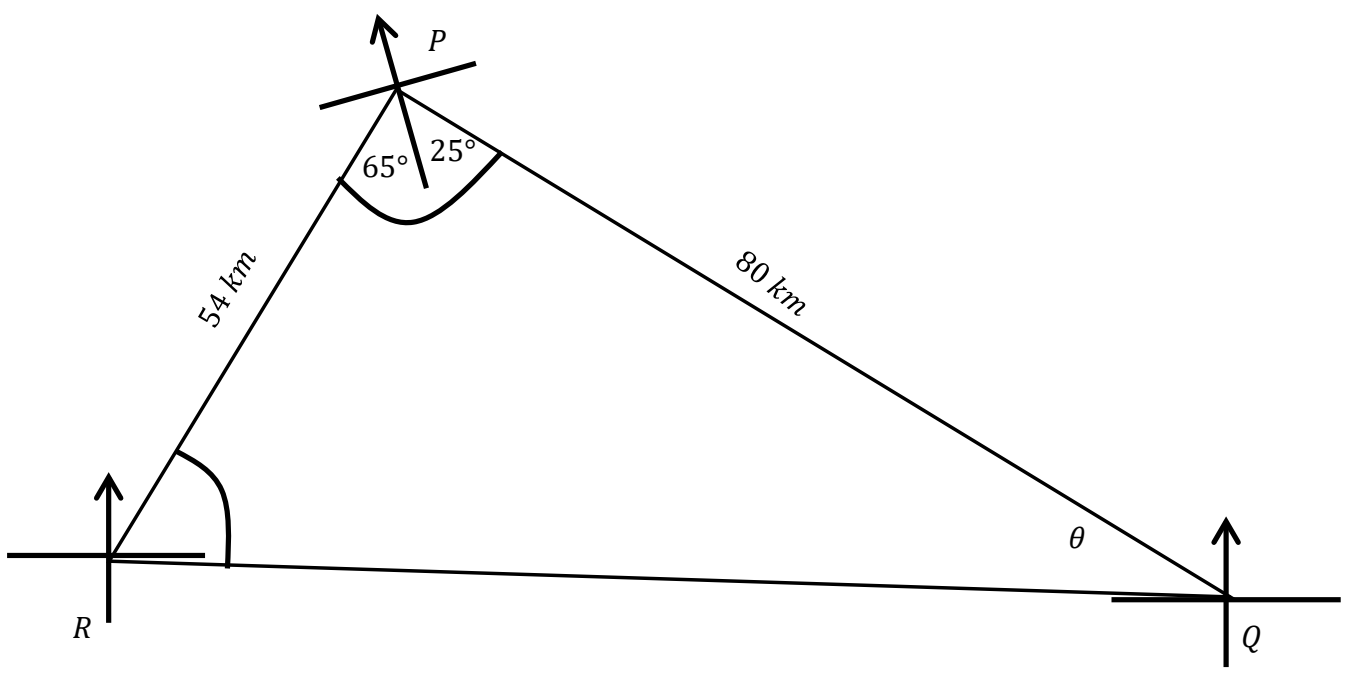


Two points $A$ and $C$, on opposite sides of a vertical pole, are on the same level ground as the foot of the pole, $B$. The angles of elevation of the top of the pole $D$ from $A$ and $C$ are $30^{\circ}$ and $48^{\circ}$ respectively. If the distance between $A$ and $C$ is $50 \mathrm{~km}$; find $|B D|$, the height of the pole. 